\title{
Acute Effects of Video Game-based Exercises in Patients Receiving Chemotherapy After Breast Cancer Surgery - A Pilot Study
}

\author{
(1) Özlem FEYZioĞLU,' (i) Özgül ÖZTÜRK,' (i) Selvi DiNÇER, ${ }^{2}$ (I) Arzu AKAN
}

'Department of Physiotherapy and Rehabilitation, Acibadem Mehmet Ali Aydinlar University Faculty of Health Sciences, Istanbul-Turkey 2Department of Radiation Oncology, Professor Doctor Cemil Tascioglu City Hospital, Istanbul-Turkey

${ }^{3}$ Department of Breast and Endocrine Surgery, Professor Doctor Cemil Tascioglu City Hospital, Istanbul-Turkey

\begin{abstract}
OBJECTIVE
Virtual reality programs, which have developed rapidly with the advancement of technology, have led to the development of alternative treatment methods preferred in rehabilitation. This study aimed to investigate the acute effects of a video game-based exercise program applied after breast cancer surgery on the upper extremity functionality, pain severity, and the level of fatigue.
\end{abstract}

\section{METHODS}

Fifteen female patients aged between 30 and 60 years $(50.13 \pm 8.79)$ who completed their $12^{\text {th }}$ week after breast cancer surgery and were received adjuvant chemotherapy treatment were randomly included in this pre-test and post-test study. The patients were performed a 30-min video game-based exercise program. The muscle strength, range of motion (ROM), pain and fatigue level assessments were performed before and after the video game-based exercises. The level of exercise pleasure was determined with the modified visual analog scale.

\section{RESULTS}

Shoulder flexion, abduction, and external rotation ROM significantly increased after video game-based exercise program. No difference was detected for shoulder abduction muscle strength ( $p>0.05)$ and pain level significantly increased $(\mathrm{p}<0.05)$. The average exercise pleasure level is $4.5 / 5$ and the average fatigue level was 11.13/20.

\section{CONCLUSION}

Video game-based exercises provided improvement in ROM of the shoulder joint without causing fatigue. Studies with different treatment durations are needed to minimize the increase in pain level.

Keywords: Breast cancer; chemotherapy; video game; virtual reality; Xbox Kinect.

Copyright $\odot$ 2022, Turkish Society for Radiation Oncology

\section{Introduction}

Breast cancer is the most leading cause of malignancy among women in the world. The survival rate of breast cancer has increased by $20-30 \%$ in the past $5-10$ years. As a result of this increase, it is necessary to focus on the problems that the patients suffered after the surgery or other cancer treatments. [1]

Treatment approaches after breast cancer surgery are adjuvant chemotherapy, radiotherapy, and endocrine therapy.[2] Adjuvant therapies such as chemotherapy and endocrin therapy are effective in reducing the risk of 
cancer recurrence,[3] but lead to impairments in physical functions.[4] Cancer and treatment-related symptoms become a major stress factor and studies have shown that the rate of depression is higher in patients receiving chemotherapy.[5] Depression and fatigue as a result of the systemic effects of chemotherapy cause poor quality of life.[6] Another side effect of chemotherapy which is commonly seen in muscles, joints, and bones.[7] Postsurgical acute pain sometimes cannot be suppressed and turns into persistent and chronic pain, caused by infection, seroma, and hematoma caused by surgery.[8]

Multimodal therapy methods have been used to increase range of motion (ROM) of the shoulder joint and to achieve pain relief. Strengthening and stretching exercises and self-mobilization techniques that started 4-6 weeks after surgery have revealed significant improvements in pain and ROM.[9] Task-oriented therapy approaches involving repetitive multiple movement patterns are also superior to exercises only in patients with musculoskeletal disorders.[10]

The importance of technology in the rehabilitation field is increasing rapidly and new technologies provide more engagement of patients in their usual care and therapy programs.[11] Virtual reality provides better upper limb functionality at least as good results of usual care which results in improving daily life activities.[12]

Xbox 360 Kinect $^{\text {tw }}$ (Redmond, WA) is a virtual reality method that can be easily adapted in clinical practice. The most basic feature of Xbox Kinect ${ }^{\mathrm{tm}}$ is interpreting and transmitting sound, image and depth stream data to the interface with its microphone and three-dimensional depth sensors. Xbox Kinect ${ }^{\mathrm{Tw}}$ captures the movements of the human body and transfers them to the computer.[13] As a product of rapidly developing video games technologies that do not require a controller, Xbox 360 Kinect $^{\mathrm{Tm}}$ contributes to the current physiotherapy programs.[14]

To the best of our knowledge, no study has been planned to investigate the acute effects of the video basedexercise program on the upper extremity functionality and fatigue in patients who received chemotherapy after breast cancer surgery. This study was planned to investigate the acute effects of the video game-based physiotherapy program after breast cancer surgery on upper extremity dysfunction, pain, and fatigue.

\section{Materials and Methods}

\section{Study Type}

The study has been conducted between November 2019 and May 2020 in patients who had surgery and chemo- therapy in Ministry of Health Prof. Dr. Cemil Taşçığlu City Hospital Departments of Radiation Oncology and General Surgery. This study has been approved by Acibadem Mehmet Ali Aydınlar University Ethics Committee on 07.02.2019 (Number: 2019-3/15). In addition, permission was obtained from the hospital where the study was conducted. The participants gave their written and verbal consent. Our study was carried out in accordance with the 2008 Principles of the Declaration of Helsinki.

\section{Participants}

A total of 24 patients were evaluated and nine patients who did not meet the inclusion criteria were excluded from the study. Fifteen patients aged between 30 and 60 years who had undergone unilateral mastectomy and completed 12 weeks after surgery were included in the study by simple randomization. All patients were received neoadjuvant chemotherapy. In addition, after the surgery all patients were received at least two cycles of chemotherapy or receiving chemotherapy and were able to continue their usual daily life activities. The exclusion criteria were as; complications due to the surgery, participation in a post-surgical physiotherapy program, neurological diseases that would affect balance and coordination, the existence of vision problems.

\section{Treatment}

Xbox Kinect 360 video games were selected considering the functional limitations experienced by the patients. The selected video games were qualified to increase the functionality of the upper extremities and especially consisted of shoulder flexion, abduction, internal, and external rotation movements. In line with the literature, we chose Kinect Sports I Beach volleyball, Bowling, Boxing, and Fruit Ninja were played. The effectiveness of the games have been seen in another our study where we conducted 6 weeks of video gamebased exercise training.[15] Since the patients had not experienced video games before, they had a warm-up and adaptation session with a different video game for $5 \mathrm{~min}$. Later, the patients had a total of $30 \mathrm{~min}$ of video game-based exercises under the supervision of an experienced physiotherapist. Patients were excluded if they felt tired to complete the exercises.

\section{Outcome Measures}

Patients were evaluated before and after a single session video game-based exercise. The demographic and clinical data were recorded on an information form. Shoulder abduction muscle strength was assessed with a hand-held dynamometer; shoulder joint ROM with a 
digital goniometer, pain level with visual analog scale (VAS), the perceived fatigue level with Modified Borg Scale and the degree of exercise pleasure with "Modified Visual Analog Scale."

\section{Pain Severity}

Visual analog scale (VAS) was used to determine the pain severity. Patients were asked to rate their current pain level on a $10-\mathrm{cm}$ horizontal line in which "0" indicates no pain and " 10 " indicates the worst possible pain.[16,17]

\section{ROM}

Shoulder joint flexion, abduction, and external rotation ROM were assessed with a digital goniometer (Baseline Digital Goniometer).[18,19] The assessments were carried out in the supine position. All measurements were performed 3 times, the mean value was recorded and the same physiotherapist conducted all measurements.

\section{Muscle Strength}

The strength of shoulder abductor muscles was evaluated with J Tech Commender Muscle Tester (Salt Lake City, Utah, USA) hand-held dynamometer. The patients were asked to position their shoulder at $90^{\circ}$ and to hold their arms against the applied force. The strength value was recorded as kilograms. Muscle contraction was continued for $5 \mathrm{~s}$ and $30 \mathrm{~s}$ of rest were given to prevent fatigue. Each measurement was repeated 3 times, the mean value was considered for analysis.[20]

\section{The Pleasure of Exercise}

The perceived pleasure of exercise was determined with Modified VAS which is graded from 0 to 5 and " 0 " indicates "disagree" and " 5 " indicates "completely agree." The patients were asked to answer "Do you feel pleasure when you are exercising?" and rate their level of pleasure.[21]

\section{Perceived Fatigue Level}

Perceived fatigue was assessed to observe the exercise tolerance and Borg Scale was used to determine the fatigue level. Borg Scale was ranged the fatigue with "6" indicates none, "7-8" very very light, "9-10" very light, "11-12" fairly light," "13-14" somewhat hard, "15-16" hard, "17-18" very hard, and "19-20" very very hard.[22]

\section{Sample Size and Statistical Analysis}

Sample size was determined based on pain severity from a study performed by Aguirre-Carvajal et al.[23] Based on this study, t-test was used to determine the sample size. At least 13 persons were found to be necessary for strength of 0.80 with an alpha level of 0.05 . We included 15 subjects in our study. Statistical analysis was performed using the Statistical Package for the Social Sciences version 21.0 software package (IBM Corp., Armonk, NY, USA). Descriptive data were presented as mean \pm standard deviation, frequency and percentage (\%). The Shapiro-Wilk test was used to check the normality of the data.

The paired t-test was used to determine whether the differences between pre- and post-intervention measurements in the treatment group. $\mathrm{P}<0.05$ was considered statistically significant.

\section{Results}

Fifteen patients with a mean age of $50.12 \pm 8.79$ were included in the study. Of all participants, $46.6 \%$ were diagnosed with the right side and $53.4 \%$ were left side breast cancer. Breast conserving surgery and axillary curettage were performed in $53 \%$ of the patients, while mastectomy and axillary curettage surgery were performed in $46 \%$ of the patients. The mean number of lymph nodes removed was 14.3 and none of the patients had distant tissue metastases. More half of the patients had Stage IIB tumor. Baseline demographic characteristics of the participants are shown in Table 1.

Comparison of the outcome measures before and after the single session video game-based exercise program is summarized in Table 2. There were significant differences for shoulder joint flexion, abduction, and external rotation ROM $(\mathrm{p}<0.05)$. The pain severity significantly increased after the treatment $(\mathrm{p}>0.05)$ and no difference was detected for shoulder abduction muscle strength $(\mathrm{p}>0.05)$. Mean perceived fatigue was $11.13 \pm 2.69$ and mean pleasure of exercise of participants value was $4.5 \pm 0.5$.

\section{Discussion}

This study investigated the acute effects of video gamebased exercise program in patients who had undergone breast cancer surgery and were receiving chemotherapy on the upper extremity functionality pain and fatigue. Our results showed that video game-based exercises improved shoulder ROM and fatigue level, however, increased pain severity. Furthermore, patients performed the exercises without getting bored.

Virtual reality-based therapy approaches are getting more attention in both clinical practice and researches and studies with long follow-up periods have 


\begin{tabular}{|c|c|c|}
\hline Variables & $\begin{array}{c}\text { Mean } \pm \text { SD } \\
(n=15)\end{array}$ & $\begin{array}{c}\text { Min-max } \\
(n=15)\end{array}$ \\
\hline Age (years) & $50.13 \pm 8.79$ & $30-65$ \\
\hline Height (m) & $1.58 \pm 0.05$ & $1.45-1.68$ \\
\hline Weight (kg) & $72 \pm 11.7$ & $51-100$ \\
\hline BMI $\left(\mathrm{kg} / \mathrm{m}^{2}\right)$ & $29.6 \pm 4.41$ & 19.8-39.1 \\
\hline \multicolumn{3}{|l|}{ Affected side $(n=15)$} \\
\hline Right & $7 / 15$ & \\
\hline Left & $8 / 15$ & \\
\hline R/L (\%) & $46.7 / 53.3$ & \\
\hline \multicolumn{3}{|c|}{ Clinical tumor categories, (\%) } \\
\hline $\mathrm{T}_{1} \mathrm{~N}_{1}$ & $1 / 15(6.6)$ & \\
\hline $\mathrm{T}_{2} \mathrm{~N}_{1}$ & $8 / 15(53.3)$ & \\
\hline $\mathrm{T}_{2} \mathrm{~N}_{2}$ & $1 / 15(6.6)$ & \\
\hline $\mathrm{T}_{2}^{2} \mathrm{~N}_{3}$ & $2 / 15(13.3)$ & \\
\hline $\mathrm{T}_{3}^{2} \mathrm{~N}_{2}^{3}$ & $1 / 15(6.6)$ & \\
\hline $\mathrm{T}_{4} \mathrm{~N}_{3}$ & $2 / 15(13.3)$ & \\
\hline \multicolumn{3}{|l|}{ Tumor stage, (\%) } \\
\hline$\| A$ & $1 / 15(6.6)$ & \\
\hline IIB & $8 / 15(53.3)$ & \\
\hline IIIA & $2 / 15(13.3)$ & \\
\hline IIIC & $4 / 15(26.6)$ & \\
\hline \multicolumn{3}{|l|}{ Surgery type, (\%) } \\
\hline $\mathrm{BSC}+\mathrm{AC}$ & $8 / 15(53.3)$ & \\
\hline Mastectomy+AC & $7 / 15$ (46.6) & \\
\hline \multicolumn{3}{|l|}{ NRLN } \\
\hline Mean (Min-max) & $14.33(1-32)$ & \\
\hline \multicolumn{3}{|l|}{ Metastasis ratio } \\
\hline$M_{0}$ & $15 / 15$ & \\
\hline
\end{tabular}

SD: Standard deviation; min: Minimum; max: Maximum; BMI: Body mass index; BSC: Breast conserving surgery; AC: Axillary curettage; NRLN: Number of excised lymph nodes

shown their effectiveness with strong evidence.[24] Xbox Kinect 360 has been utilized to conduct kinematic analysis of upper extremity and to evaluate functionality in patients with breast cancer.[25] Our study has the potential to contribute evidence about acute effects of video game-based exercises on the upper extremity functionality in patients with breast cancer.

Due to the decrease in mortality related to breast cancer over the years, clinicians should focus on the short- and long-term side effects of the treatment approaches. Especially, mobility of the shoulder joint complex decreases between $12 \%$ and $16 \%$ in patients who had undergone breast cancer surgery compared to healthy individuals.[26] Post-surgical exercise program resulted in $9.72^{\circ}$ increase in shoulder abduction ROM in patients receiving adjuvant therapy.[27] In our study despite single-session, shoulder abduction ROM increased with an average of $4.24^{\circ}$. Future studies with longer treatment periods may show more improvement in shoulder joint ROM.[27]

Pain is the most common complication during the post-surgical period. When the painful surgical and chemotherapy process is handled successfully, the chronic pain that occurs in patients will not be associated with chemotherapy.[28] Although different treatment modalities have been used to suppress chemotherapy-induced pain, it has been reported that virtual reality that applied during the chemotherapy sessions is the most effective method in coping with pain.[24,29] In our study, there was a significant increase in pain severity after video game-based exercises. We think that the reason for this increase may be related to the application of virtual reality not on the day which patients receive chemotherapy drugs rather during the disturbing chemotherapy sessions. Because the distracting effect of the virtual reality application could not be utilized. Furthermore, an increase in pain severity may be caused by the design of our treatment program in which the games were planned to move the upper extremity in all directions and the treatment duration was

Table 2 Mean and standart deviation of outcome variables at pre- treatment and post-treatment

\begin{tabular}{|c|c|c|c|c|}
\hline & $\begin{array}{c}\text { Pre-treatment } \\
(n=15) \\
\text { Mean } \pm(S D)\end{array}$ & $\begin{array}{c}\text { Post-treatment } \\
(n=15) \\
\text { Mean } \pm(S D)\end{array}$ & Mean differences & $\mathbf{p}^{*}$ \\
\hline VAS for pain (0-10) & $2.80 \pm 2.07$ & $3.60 \pm 2.22$ & $0.80 \pm 1.26$ & 0.028 \\
\hline Flexion shoulder, deg & $155.18 \pm 20.09$ & $160.41 \pm 20.36$ & $5.22 \pm 4.32$ & 0,000 \\
\hline Abduction shoulder, deg & $144.67 \pm 23.86$ & $148.98 \pm 24.47$ & $4.24 \pm 3.38$ & 0.000 \\
\hline ER shoulder, deg & $81.56 \pm 9.13$ & $83.19 \pm 9.09$ & $1.62 \pm 1.98$ & 0.007 \\
\hline Shoulder abduction (kg) & $6.27 \pm 1.84$ & $6.32 \pm 1.93$ & $0.05 \pm 0.64$ & 0.762 \\
\hline The pleasure of exercise $(0-5)$ & \multicolumn{2}{|c|}{$4.50 \pm 0.5$} & & \\
\hline Perceived fatigue level & \multicolumn{2}{|c|}{$11.13 \pm 2.69$} & & \\
\hline
\end{tabular}

SD: Standart deviation; VAS: Visual analog scale; ER: External rotation. *p values obtained from the Independent t-test 
$30 \mathrm{~min}$. Most of the studies were planned with patients who were in a static position in the literature.

According to the American Society of Clinical Oncology data, shoulder muscle strength decreases after mastectomy.[30] Especially, a decrease in muscle strength is more prominent in patients receiving chemotherapy due to the decline in the mitochondrial capacity of muscle cells. Decreased muscle strength causes impairment in functionality and poor quality of life. Therefore, the most important goal in cancer treatment is to increase muscle strength.[31] In our study, no significant change was found in shoulder abduction muscle strength. The single-session virtual reality treatment seems not effective in increasing muscle strength, it is necessary to prescribe more treatment sessions to achieve this goal. Patients' pleasure of exercise is related to the level of exercise. Furthermore, experiencing and learning different exercises make exercising more enjoyable.[21,32]

Pleasure of exercise plays a key role in encouraging sedentary women for exercise and physical activity diagnosed with breast cancer.[33] Our patients enjoyed when performing video game-based exercises (Average:4.5/5). Despite the increased pain severity during the exercises, the high rate of exercise pleasure indicates that the patients had a high level of exercise tolerance and exercise tolerance can be improved in this patient group.

Schmidt et al.[34] reported that the perceived fatigue level should be between 11 and 14 according to the Borg Scale during endurance and resistive exercises. It was also stated that the duration of the exercises was associated with fatigue. The perceived fatigue level of 12 and above was defined as a medium or high level of fatigue.[35] The perceived level of fatigue during the 30-min virtual game-based exercise program was $11.13 \pm 2.69$ which was below 12 . Considering the level of fatigue, it has been observed that the participants were performed exercises comfortably. The exercise program was completed without any fatigue that would require stopping the program. Therefore, breast cancer patients receiving adjuvant chemotherapy can participate in a virtual game-based exercise program and complete the exercises with pleasure.

The study is not without limitations. First, our study did not include a control group performing usual care or conventional physiotherapy. Second, this is a singlesession pilot study since we did not conduct our study with larger sample size.

This is the first study investigating the acute effects of video game-based exercises applied to patients receiving chemotherapy drugs with breast cancer.

\section{Conclusion}

This pilot single-session study has shown that commercially available Xbox 360 Kinect video games can be used to increase upper extremity functionality and to provide high level of exercise pleasure without causing fatigue. More studies are needed to determine the optimal duration and frequency of this method to improve functionality without increasing pain.

Peer-review: Externally peer-reviewed.

Conflict of Interest: All authors declared no conflict of interest.

Ethics Committee Approval: The study was approved by the Acıbadem Mehmet Ali Aydınlar University Medical Research Ethics Committee (No: 2019-3/15, Date: 07/02/2019).

Financial Support: This study has received no financial support.

Authorship contributions: Concept - Ö.F., Ö.Ö., S.D., A.A.; Design - Ö.F., Ö.Ö., S.D., A.A.; Supervision - Ö.F., Ö.Ö., S.D., A.A.; Funding - S.D.; Materials - S.D., A.A.; Data collection and/or processing - Ö.F., Ö.Ö.; Data analysis and/ or interpretation - Ö.F., Ö.Ö.; Literature search - Ö.F., Ö.Ö., S.D., A.A.; Writing - Ö.F., Ö.Ö., S.D.; Critical review - Ö.F., Ö.Ö., S.D., A.A.

\section{References}

1. Ewertz M, Jensen AB. Late effects of breast cancer treatment and potentials for rehabilitation. Acta Oncol 2011;50(2):187-93.

2. Zdenkowski N, Butow P, Tesson S. A systematic review of decision aids for patients making a decision about treatment for early breast cancer. Breast 2016;26:31-45.

3. Anampa J, Makower D, Sparano JA. Progress in adjuvant chemotherapy for breast cancer: An overview. BMC Med 2015;13:1-13.

4. Galantino ML, Stout NL. Exercise interventions for upper limb dysfunction due to breast cancer treatment. Phys Ther 2013;93(10):1291-7.

5. So WK, Marsh G, Ling W, Leung FY, Lo JC, Yeung M, et al. Anxiety, depression and quality of life among Chinese breast cancer patients during adjuvant therapy. Eur J Oncol Nurs 2010;14(1):17-22.

6. Van Vulpen JK, Peeters PH, Velthuis MJ, Wall E, May AM. Effects of physical exercise during adjuvant breast cancer treatment on physical and psychosocial dimensions of cancer-related fatigue: A meta-analysis. Maturitas 2016;85:104-11.

7. Hellerstedt-Börjesson S, Nordin K, Fjällskog ML, Holmström IK, Arvin C. Women with breast cancer: 
Experience of chemotherapy-induced pain: Triangulation of methods. Cancer Nurs 2015;38(1):31-9.

8. Andersen KG, Kehlet HJ. Persistent pain after breast cancer treatment: A critical review of risk factors and strategies for prevention. J Pain 2011;12(7):725-46.

9. De Groef A, Van Kampen M, Dieltjens E, Christiaens MR, Neven P, Geraerts I, et al. Effectiveness of postoperative physical therapy for upper-limb impairments after breast cancer treatment: A systematic review. Arch Phys Med Rehabil 2015;96(6):1140-53.

10. Arman N, Tarakci E, Tarakci D, Kasapcopur Ö. Effects of video games-based task-oriented activity training (Xbox 360 Kinect) on activity performance and participation in patients with juvenile idiopathic arthritis: A randomized clinical trial. Am J Phys Med Rehabil 2019;98(3):174-81.

11. Öztürk Ö, Feyzioğlu Ö. Virtual reality technologies and chronic pain. Türk Klinikleri J Tradit Complem Med 2020;3(2):211-6.

12. Yang Z, Rafiei MH, Hall A, Thomas C, Midtlien HA, Hasselbeach A, et al. A novel methodology for extracting and evaluating therapeutic movements in gamebased motion capture rehabilitation systems. J Med Syst 2018;42(12):1-14.

13. Parry I, Carbullido C, Kawada J, Bagley A, Sen S, Greenhalgh D, et al. Keeping up with video game technology: Objective analysis of Xbox Kinect ${ }^{\text {tm }}$ and PlayStation $3 \mathrm{Move}^{\mathrm{Tu}}$ for use in burn rehabilitation. Burns 2014;40(5):852-9.

14. Fager SK, Burnfield JM. Patients' experiences with technology during inpatient rehabilitation: Opportunities to support independence and therapeutic engagement. Disabil Rehabil Assist Technol 2014;9(2):121-7.

15. Feyzioğlu Ö, Dinçer S, Akan A, Algun ZC. Is Xbox 360 Kinect-based virtual reality training as effective as standard physiotherapy in patients undergoing breast cancer surgery? Support Care Cancer 2020;28(9):4295-303.

16. Beurskens $\mathrm{CH}$, van Uden CJ, Strobbe LJ, Oostendorp RA, Wobbes T. The efficacy of physiotherapy upon shoulder function following axillary dissection in breast cancer, a randomized controlled study. BMC Cancer 2007;7:1-6.

17. Carlsson AM. Assessment of chronic pain. I. Aspects of the reliability and validity of the visual analogue scale. Pain 1983;16(1):87-101.

18.Zengin Alpozgen A, Razak Ozdincler A, Karanlik $\mathrm{H}$, Yaman Ağaoğlu F, Narin AN. Effectiveness of Pilates-based exercises on upper extremity disorders related with breast cancer treatment. Eur J Cancer Care 2017;26(6):e12532.

19. Carey MA, Laird DE, Murray KA, Stevenson JR. Reliability, validity, and clinical usability of a digital goniometer. Work 2010;36(1):55-66.
20. Belmonte R, Messaggi-Sartor M, Ferrer M, Pont A, Escalada F. Prospective study of shoulder strength, shoulder range of motion, and lymphedema in breast cancer patients from pre-surgery to 5 years after ALND or SLNB. Support Care Cancer 2018;26(9):3277-87.

21. Hagberg L, Lindahl B, Nyberg L, Hellénius ML. Importance of enjoyment when promoting physical exercise. Scand J Med Sci Sports 2009;19(5):740-7.

22. Chen MJ, Fan X, Moe ST. Criterion-related validity of the Borg ratings of perceived exertion scale in healthy individuals: a meta-analysis. J Sports Sci 2002;20(11):873-99.

23. Aguirre-Carvajal M, Marchant-Pérez P. Description of the effect of exercises with virtual reality on the ipsilateral upper limb in women after mastectomy. Gaceta Mex Oncol 2015;14(4):204-9.

24. Chirico A, Lucidi F, De Laurentiis M, Milanese C, Napoli A, Giordano A. Virtual reality in health system: Beyond entertainment. A mini-review on the efficacy of VR during cancer treatment. J Cell Physiol 2016;231(2):275-87.

25. Uhm KE, Lee S, Kurillo G, Han JJ, Yang HY, Yoo $\mathrm{YB}$, et al. Usefulness of Kinect sensor-based reachable workspace system for assessing upper extremity dysfunction in breast cancer patients. Support Care Cancer 2020;28(2):779-86.

26. Soriano-Maldonado A, Carrera-Ruiz Á, Díez-Fernández DM, Esteban-Simón A, Maldonado-Quesada M, Moreno-Poza N, et al. Effects of a 12-week resistance and aerobic exercise program on muscular strength and quality of life in breast cancer survivors: Study protocol for the EFICAN randomized controlled trial. Medicine 2019;98(44):e17625.

27. McNeely ML, Campbell K, Ospina M, Rowe BH, Dabbs K,Klassen TP, et al. Exercise interventions for upper-limb dysfunction due to breast cancer treatment. Cochrane Database Syst Rev 2010;6:CD005211.

28. Wang L, Guyatt GH, Kennedy SA, Romerosa B, Kwon HY, Kaushal A, et al. Predictors of persistent pain after breast cancer surgery: A systematic review and meta-analysis of observational studies. CMAJ 2016;188:E352-61.

29. Lovelace DL, McDaniel LR, Golden D. Long-term effects of breast cancer surgery, treatment, and survivor care. J Midwifery Womens Health 2019;64(6):713-24.

30. Tantawy SA, Kamel DM. The effect of kinesio taping with exercise compared with exercise alone on pain, range of motion, and disability of the shoulder in postmastectomy females: A randomized control trial. J Phys Ther Sci 2016;28(12):3300-5.

31. Klassen O, Schmidt ME, Ulrich CM, Schneeweiss A, Potthoff K, Steindorf K, et al. Muscle strength in breast cancer patients receiving different treatment regimes. J Cachexia Sarcopenia Muscle 2017;8(2):305-16. 
32. Allender S, Cowburn G, Foster C. Understanding participation in sport and physical activity among children and adults: A review of qualitative studies. Health Educ Res 2006;21(6):826-35.

33. Gho SA, Munro BJ, Jones SC, Steele JR. Perceived exercise barriers explain exercise participation in Australian women treated for breast cancer better than perceived exercise benefits. Phys Ther 2014;94(12):1765-74.
34. Schmidt T, Weisser B, Duerkop J, Jonat W, Mackelenbergh MV, Röcken C, et al. Comparing endurance and resistance training with standard care during chemotherapy for patients with primary breast cancer. Anticancer Res 2015;35(10):5623-9.

35. Johnsson A, Johnsson A, Johansson K. Physical activity during and after adjuvant chemotherapy in patients with breast cancer. Physiotherapy 2013;99(3):221-7. 